Geografia e Ordenamento do Território, Revista Eletrónica

Centro de Estudos de Geografia e Ordenamento do Território



Centro de Estudos de Geografia

e Ordenamento do Território http://cegot.org

ISSN: 2182-1267

Almeida, A. Campar

Faculdade de Letras da Universidade de Coimbra

CEGOT

campar@fl.uc.pt

\title{
As dunas litorais entre Quiaios e Aveiro
}

Referência: Almeida, A. C. (2012). As dunas entre Quiaios e Aveiro. Revista de Geografia e Ordenamento do Território, n.o 2 (Dezembro). Centro de Estudos de Geografia e Ordenamento do Território. Pág. 7 a 23

\section{Resumo}

O objetivo deste trabalho é discutir, do ponto de vista genético, a morfologia, das dunas componentes do campo dunar mais recente entre Aveiro e Quiaios na região litoral centro norte de Portugal. Procura-se demonstrar que não há só um tipo de dunas, em especial transversas ou parabólicas, mas que as dunas são, na maioria, lineares atuadas por ventos dominantemente bimodais. A distribuição dos seus flancos abruptos quer para norte quer para sul em diferentes setores mostra que houve transporte de areias por ventos de rumos diversos, quase opostos.

Palavras-chave: dunas lineares, transversas, parabólicas, dinâmica dunar, costa ocidental de Portugal 


\section{Abstract}

This paper aims to discuss the genesis of dune morphology, of the more recent dune field between Aveiro and Quiaios (coastal northern centre of Portugal). The inexistence of only a dune type, especially transverse or parabolic ones, is demonstrated saying that the most of them are linear dunes dominantly built by bimodal winds. Its lee face distribution, either to the north or to the south in different areas of the field, shows the evidence that sand blew from diverse and almost opposite directions.

Keywords: linear dunes, transverse dunes, parabolic dunes, dune dynamics, western coast of Portugal 


\section{Introdução}

O campo de dunas mais recentes, constituído por dunas que ainda no início do séc. XX progrediam em direção a oriente (Rei, 1940), estendido entre Quiaios e a proximidade de Ílhavo, desenvolveu-se com uma largura máxima, mas frequente, de $6 \mathrm{~km}$ ao longo de $46 \mathrm{~km}$, estreitando-se para cerca de $2 \mathrm{~km}$ no setor norte (fig.1). Apesar de ser constituído por dunas de formas variadas, as dunas dominantes têm uma disposição linear, com orientação geral W-E, embora por vezes possam fletir um pouco para ESE nos seus setores mais interiores. Muitas destas dunas têm cristas contínuas por mais de $1 \mathrm{~km}$ e aparentam uma certa regularidade no distanciamento umas das outras, em regra entre 150 e $200 \mathrm{~m}$.

O padrão linear dominante apenas se verifica na denominada terceira geração dunar (Almeida, 1997), a mais recente, diferenciada das outras gerações de dunas pela morfologia, visto dominarem dunas parabólicas nas primeiras gerações, mas principalmente pelo grau de desenvolvimento pedológico que apresentam (Almeida, 1990). Os seus solos são incipientes, Regossolos (ou Arenossolos segundo a classificação da FAO) apenas com delgado horizonte A1. Os solos das outras gerações já apresentam sinais da podzolização sendo que, num caso, o solo evoluído, com horizonte B castanho avermelhado, na segunda geração, e um Podzol, em geral humoferruginoso, por vezes endurecido no horizonte B com surraipa, nas dunas da primeira geração. Foi sobre estes últimos solos, ácidos e pobres, que se instalaram, praticaram e praticam a agricultura os gandareses já há algumas centenas de anos. Assistiram à formação das lagoas interdunares que delimitam a $E$ as dunas mais recentes, há cerca de 300 anos (Danielsen et al., 2011). Também assistiram ao persistente avanço das areias destas dunas até ao início do século XX, vendo-as cobrir, ano após ano, hectares de terrenos agricultados e deram a mão-de-obra para sobre elas semearem o pinhal, instrumento eficaz para as fixar, parando-lhes o movimento, pelo menos até agora. 
Por outro lado, nem sempre se desenvolve uma duna frontal tão alta como aquela que existe agora neste tramo da costa ocidental portuguesa ${ }^{1}$. A sua elevação deveu-se, em grande parte, à implantação de ripados paralelos e contíguos à praia, com o intuito de proteger as sementeiras de pinhal que se estavam a levar a cabo para o interior daquela duna. Ou seja, o vento, antes, transportava mais facilmente areia para o interior para a acrescentar às dunas em movimento do que agora.

Nos tempos imediatamente anteriores ao início do séc. $X X$, pela frequência dos ventos fortes do quadrante $W$, em função da permanência da situação de NAO negativa (1770-1905, seg. Clarke \& Rendell, 2006) que, à imagem do que acontece agora daria origem a maior precipitação, é natural que houvesse maior disponibilidade em areia, e apesar da fraca diminuição do nível do mar $^{2}$, o fornecimento em areia para as dunas foi muito mais importante do que agora. Daí o seu avanço para o interior.

Mas perguntas mantêm-se praticamente sem resposta convincente, como por exemplo a da razão das dunas anteriores à última geração serem dominantemente parabólicas, podendo eventualmente coalescer e dar dunas transversas de sentido NNE-SSW, como no Calvão ou mesmo na Mata de Leiria, a oriente da última crista, enquanto as mais recentes são lineares e, grosso modo, paralelas entre si.

Decerto que as condições climáticas coevas seriam diferentes. As últimas ter-se-iam formado em situação de grande disponibilidade de areia nas praias e ventos mais fortes e de rumo médio próximo de $W$ do que nas anteriores em que a vegetação se manteria (mesmo sendo arbustiva) e os ventos deveriam ser mais fracos e de rumo mais próximo de NW. O primeiro caso em situação de NAO negativa e o segundo de NAO positiva, tendo por seguro o que tem sido aceite de que no resto da Europa ocidental as dunas se formaram essencialmente com os tempos de NAO positiva e em Portugal nos de NAO negativa (Clarke \& Rendell, 2006).

A não uniformidade das formas das dunas recentes tem suscitado as suas mais diversas classificações, em regra através da generalização por um tipo. O tipo mais

\footnotetext{
${ }^{1}$ A duna, em média, tem $12 \mathrm{~m}$ de altura, mas pode ter um pouco menos em Quiaios e atingir os $16 \mathrm{~m}$ em Mira.

${ }^{2}$ Nos Estados Unidos da América estudos recentes apontam para um abaixamento de 0,1 mm/ano, entre os séculos XVI e XIX (Kemp et al., 2011).
} 
usualmente atribuído é o de dunas transversas (Noivo, 1996; Noivo \& Bernardes, 1998); mas também o de dunas oblíquas (Almeida, 1991 e 1997); assim como o de dunas parabólicas (Clarke \& Rendell, 2006). Talvez o único pecado praticado pelos autores citados é generalizarem a atribuição de praticamente só um tipo por todo o campo dunar; todos eles podem ser vistos, assim como outras formas tal como dunas barcanes, embora raras, blowouts e domos. Como hipótese pode-se aventar que as condições locais e as variações temporais do vento, assim como da alimentação sedimentar contribuíram para esta diversidade morfológica.

O objetivo deste trabalho é procurar mostrar que dificilmente se poderia desenvolver, de modo generalizado, um único e dominante tipo de dunas, em especial quando é associado a ventos unimodais, tendo em conta a morfologia das dunas atuais e a capacidade de transporte sedimentar dos ventos mais frequentes nesta área.

\section{Metodologia}

Foram escolhidas cinco áreas amostra, com superfícies de 6 a $9 \mathrm{~km}^{2}$ (Fig. 1), sendo marcadas as cristas das dunas e as vertentes ou flancos mais abruptos, correspondentes às vertentes sotavento de deposição das areias quando estiveram em movimento. Para essa identificação foram usadas fotografias aéreas de 1958, na escala aproximada de 1/25000, através de observação estereoscópica. Nesta data os pinheiros semeados nas décadas imediatamente anteriores ainda estavam pequenos e permitiam visualizar bem a morfologia dunar. Estes elementos foram confirmados com reconhecimento de campo. Foram também analisados alguns cimos amplos de dunas onde fosse possível detetar a orientação das línguas de areia que se iam sobrepondo em diferentes momentos de movimentação das areias nessas posições.

A fim de compreender a variabilidade dos ventos nesta região e especialmente a sua capacidade de transporte de sedimentos, foram analisados dados horários de ventos durante o período de 1 de Setembro de 2006 a 31 de Março de 2009, os disponíveis com fiabilidade, para o posto meteorológico da Praia de Mira e fornecidos pelo SNIRH, do INAG (Instituto Nacional da Água). Mais importante do que representar a frequência dos ventos e a sua velocidade, é o cálculo da capacidade potencial de 
transporte de areia por esse vento a qual varia de modo exponencial com a sua velocidade. Sendo assim, foi seguido o método de Fryberger (1979) para o cálculo da deriva $^{3}$ potencial de areia, tendo por base valores do limiar inferior de arranque para as areias ligeiramente diferentes, já que foram considerados os 8 nós e os 19 nós, respetivamente para areias secas e húmidas. Este método permite o cálculo da deriva potencial de areia, assim como da sua resultante e a tradução dos respetivos valores em representação vetorial, numa rosa dos ventos, com a aplicação da fórmula:

$$
D P=\left(u^{2}\left(u-u_{t}\right) / 100\right) t
$$

em que $D P$ é a deriva potencial em unidades vetoriais, $u$ é a velocidade do vento, em nós, $u_{t}$ é a velocidade limiar de arranque, em nós e $t$ é a percentagem de observações de vento acima da velocidade limiar de arranque.

A fim de ter uma noção da variabilidade dos ventos ao longo de cada mês, portanto do seu regime, calculou-se a razão entre a resultante e a deriva potencial, RDP/DP, em que valores próximos de 1 significam o grande domínio dos ventos de um rumo, ou seja unimodais, e próximos de 0 grande variabilidade de rumos, ou seja multimodais. A resultante foi determinada por cálculo vetorial, a partir dos vetores da deriva potencial de cada rumo.

A escolha da vertente abrupta das dunas como indicadora do movimento das areias e, portanto, dos ventos que the deram origem vem no sentido de se poder deduzir que nesse momento eles soprariam em ângulo perpendicular ou sempre em ângulo superior a 40 을 relativamente à crista, tidos como os ângulos favoráveis à separação do vento do contacto com a superfície e, assim, acumularem areia na vertente sotavento (Lancaster, 1989; Tsoar, 2001). Se os ventos atacarem a duna segundo ângulos inferiores a 40 으, defletem e persistem unidos à duna, mantendo o transporte de areia; neste caso, os cerca de 32-34을 de declive típicos das faces de deposição não são alcançados. Levando em conta estes princípios, a posição ocupada pelo abrupto das dunas serve como indicador do quadrante para onde soprava o vento eficaz quando da sua formação.

\footnotetext{
${ }^{3}$ Decidiu-se usar a tradução literal do drift inglês, embora se pudesse usar simplesmente transporte.
} 
Fig. 1 - Localização da área de estudo e das áreas-amostra.

(Fonte: Google Earth)

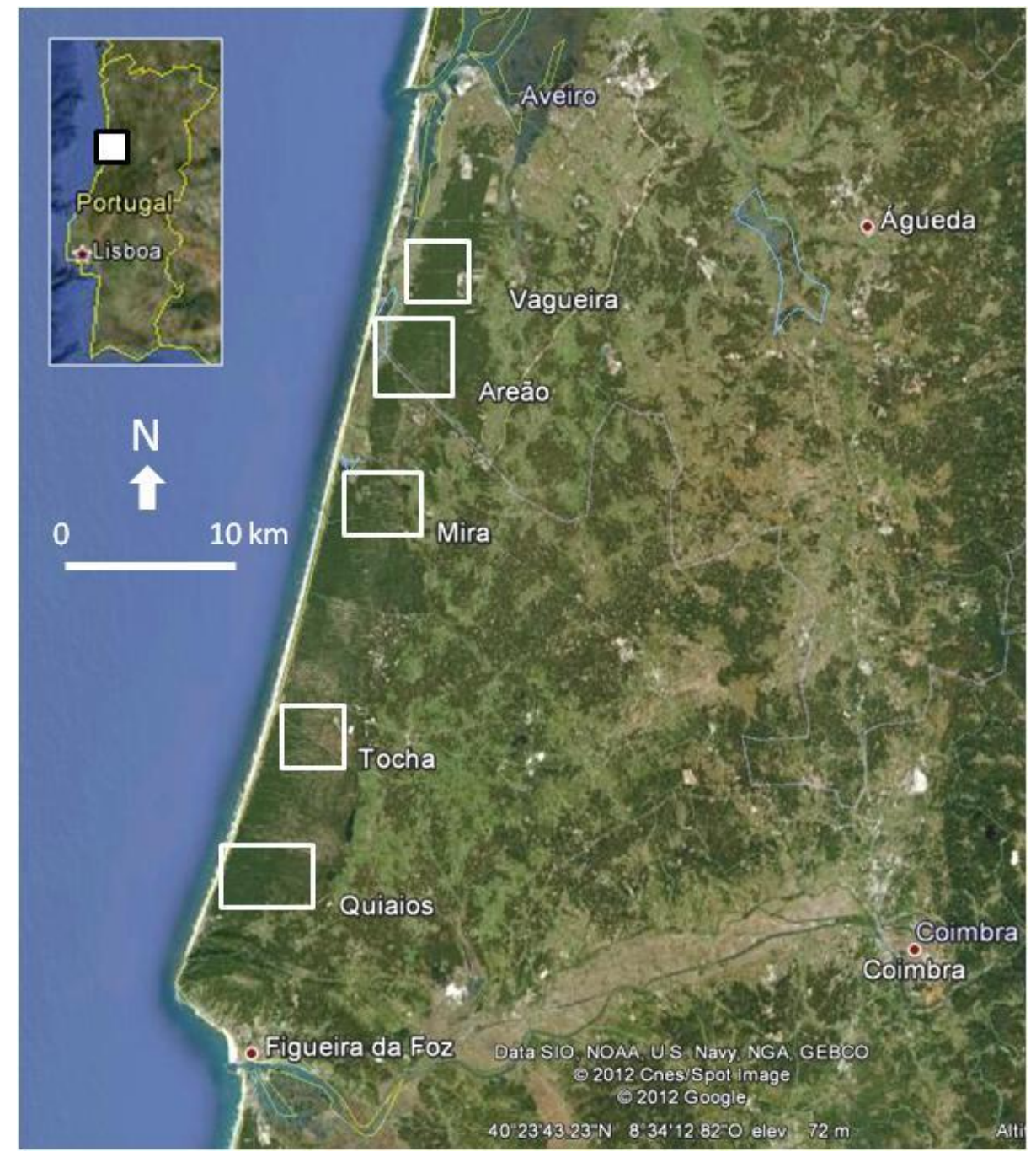

\section{Os resultados}

A observação da forma das dunas de desenvolvimento linear ao longo do campo dunar mais recente mostra que estas não são uniformes. Isso pode ser constatado percorrendo as dunas das cinco áreas-amostra escolhidas.

Na área da Vagueira (Fig. 2) nota-se haver um domínio dos abruptos, quando existem, para norte, não obstante algumas dunas os apresentarem para os dois lados, portanto simétricas, e uma faixa a sul da estrada florestal Vagueira-Vagos mostrar um domínio para sul. Um outro aspeto a salientar é a pequena extensão contínua das dunas 
lineares, embora algumas ultrapassem o quilómetro, e uma certa irregularidade no tamanho e disposição das dunas.

Fig. 2 - Área-amostra da Vagueira

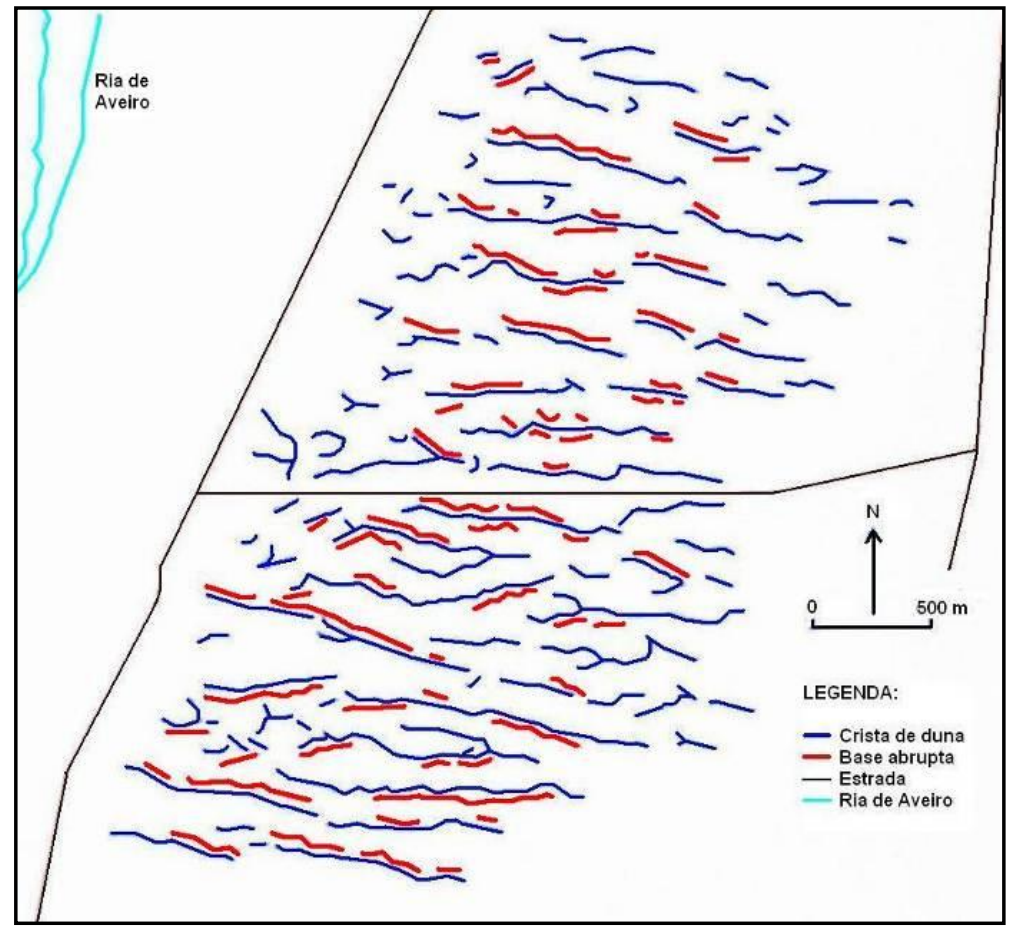

Logo a sul, na área do Areão (Fig. 3), fez-se o levantamento em dois setores, um a norte, junto à estrada florestal Areão-Calvão e outro a sul, mais próximo da estrada florestal Poço da Cruz-Seixo. No primeiro setor, há uma distinção entre uma faixa junto à estrada e para sul, com abruptos da vertente nitidamente para norte, enquanto para norte da estrada dominam os abruptos para sul. Já no setor sul, os abruptos são quase exclusivamente para sul. Mantém-se, à semelhança da primeira área, uma certa irregularidade das dunas com algumas delas com nítido efeito parabólico.

$\mathrm{Na}$ área imediatamente a sul da Praia de Mira (Fig. 4) as dunas lineares são um pouco mais regulares no espaçamento entre si e apresentam a vertente abrupta dominantemente para norte. As dunas mais ocidentais, em particular, insinuam formas parabólicas. 
Fig. 3 - Área-amostra do Areão



Fig. 4 - Área-amostra da Praia de Mira

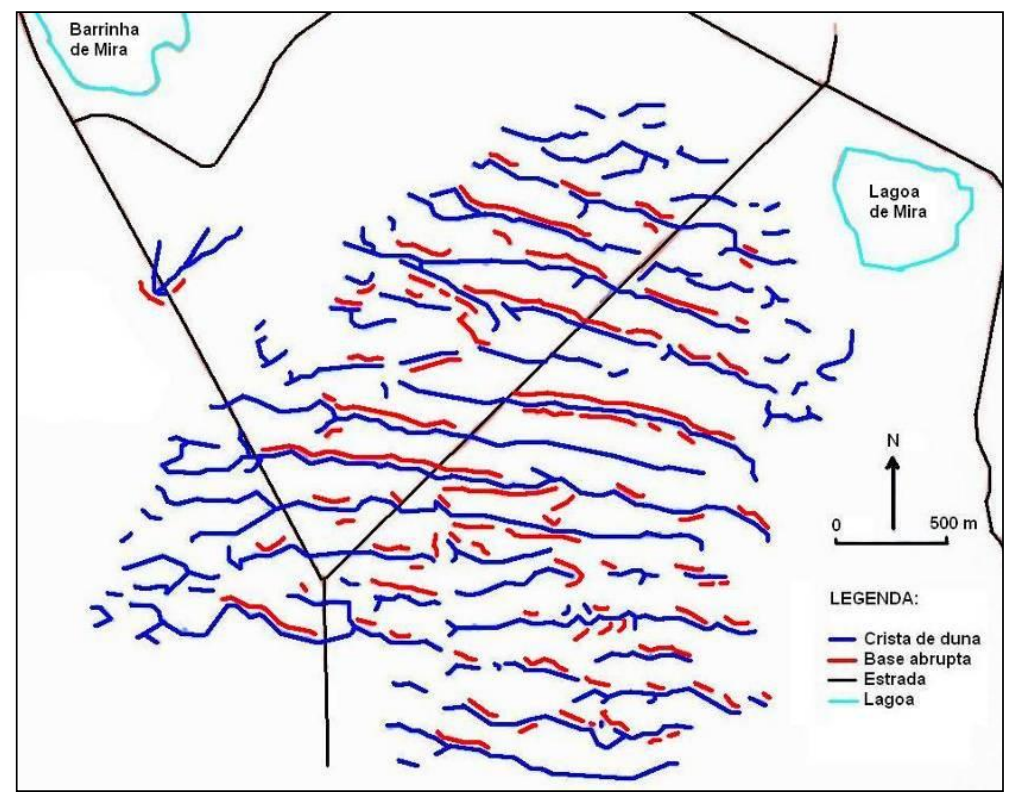

Imediatamente a oriente da Praia da Tocha (Fig. 5) distribuem-se dunas essencialmente lineares, com abrupto dominante para sul, não obstante algumas serem simétricas. Diversas terminações em gancho indiciam morfologias parabólicas. 
Fig. 5 - Área-amostra da Praia da Tocha

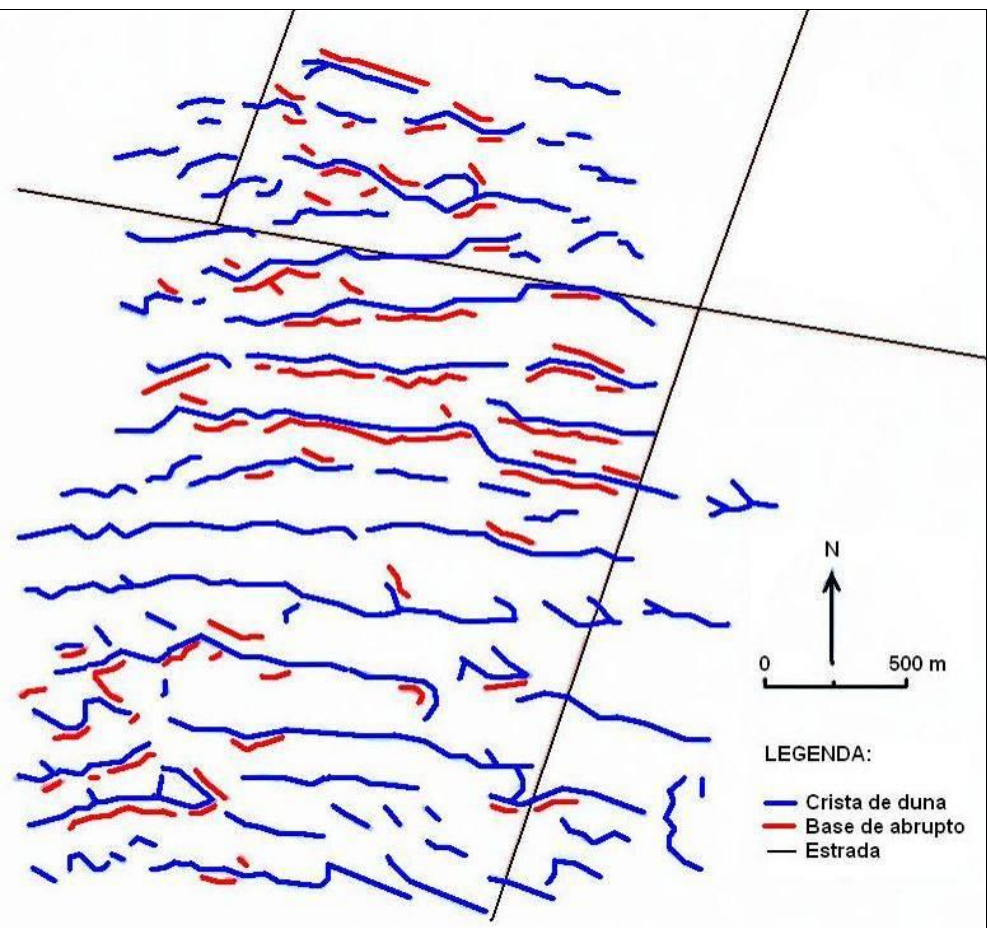

No limite sul do campo dunar, junto a Quiaios (Fig. 6), distinguem-se dois setores, um ocidental e outro oriental, com comportamentos morfológicos diferenciados, separados por uma mancha triangular central com poucas dunas. No setor oriental todas as dunas têm o abrupto para sul e vertente suave para norte, sendo portanto transversais. Já o ocidental apresenta dunas lineares com abrupto dominante para sul, mas também para norte e para os dois em simultâneo. As dunas terminam a oriente com um acréscimo nítido da altura e por uma vertente de avalanche contínua, embora irregular, com direção NNE-SSW. 
Fig. 6 - Área-amostra de Quiaios

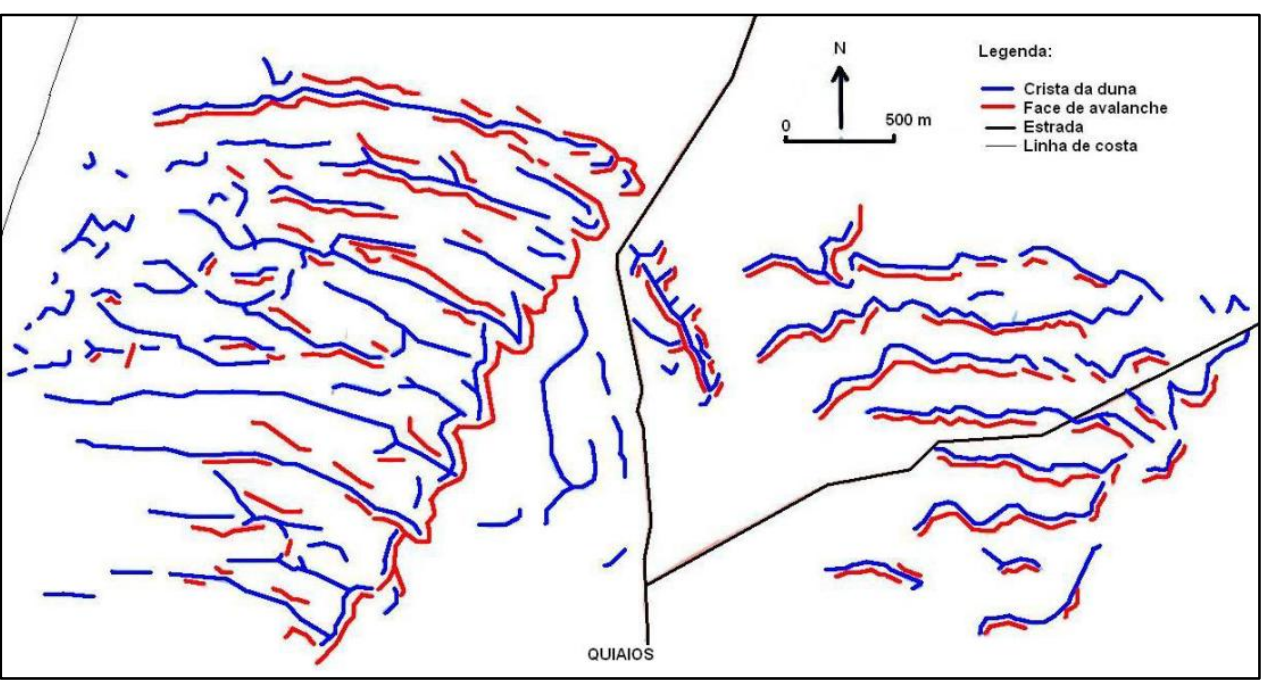

Levantamentos feitos sobre algumas cristas de dunas lineares onde estavam registadas acumulações de areia com forma linguóide, mostraram que estas apresentam orientações diversificadas. Os ventos transportadores daquela areia atuaram desde o rumo norte até ao sul, passando pelos do quadrante oeste (Fig. 7).

Fig. 7 - Formas de acumulação linguóide e parabolóide sobre duna linear.

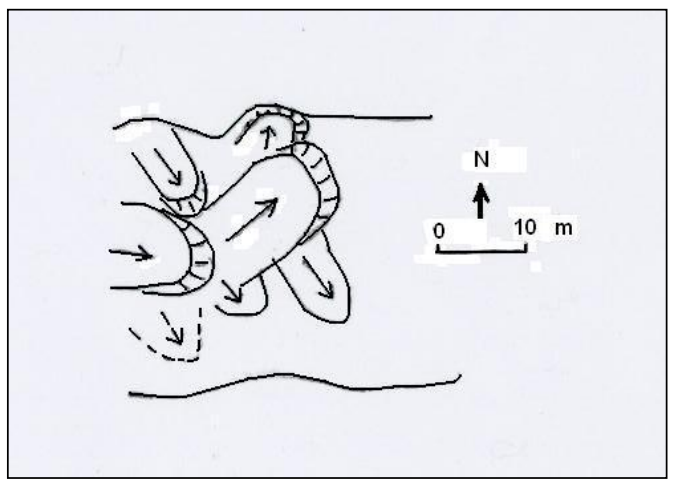

Os resultados obtidos a partir dos dados de vento e precipitação referentes ao posto da Praia de Mira, apesar da sua curta duração (não chegam a ser três anos completos) já ajudam a compreender o comportamento do vento ao longo do ano. Verifica-se que há dois períodos distintos: entre Novembro e Abril e entre Maio e Outubro (Fig. 8). No primeiro caso os rumos são mais diversificados, em regra entre norte e sudoeste e, geralmente, com dois rumos a salientarem-se, mas também com valores médios mais elevados de deriva potencial de areias. No segundo período, o mais quente, há um domínio nítido do rumo norte, embora a capacidade de transporte seja, em média, bem menor, com exceção de Outubro e Maio. 
Fig. 8 - Rosa-dos-ventos, em termos de Deriva Potencial de areias, para o posto de Praia de Mira, Set. 2006 - Mar. 2009

(Fonte dos dados: SNIRH, INAG)
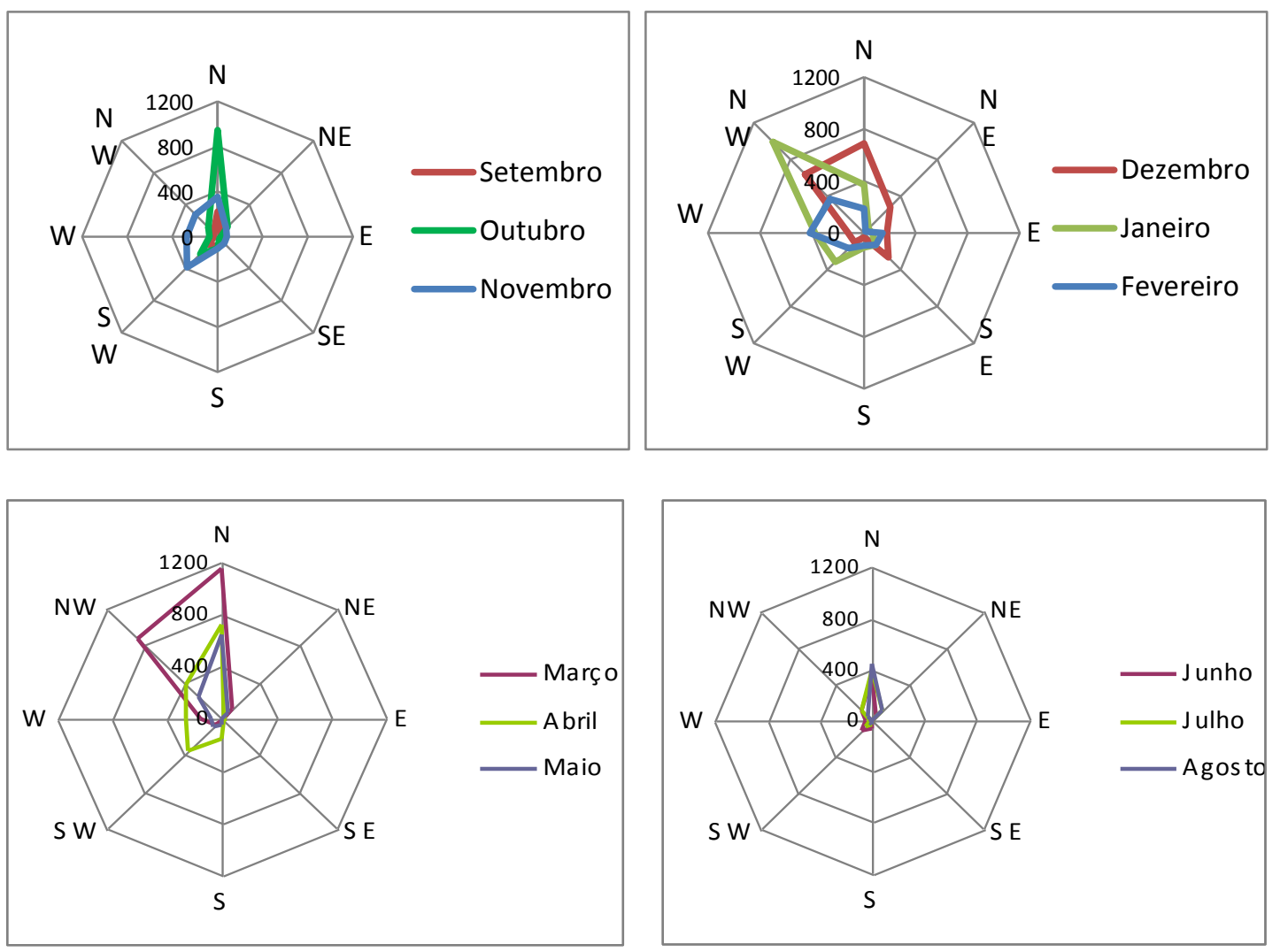

Enquanto a figura 8 permite ter uma visão geral sobre a importância relativa do transporte de areia pelos vários rumos ao longo do ano, o Quadro I permite uma análise mais pormenorizada da variabilidade dessa capacidade de transporte. Assim, o rumo dominante é na maioria de norte, apenas se excetuam novembro de SW, janeiro de NW e fevereiro de W. O segundo rumo mais frequente também mostra um domínio de NW, mas há cinco meses com outro rumo, sendo dois deles de SW. Conjugando os vários rumos calculados, determina-se a resultante que, como era de esperar, ronda normalmente o norte ( $N$, NNW e NW), com exceção dos meses de novembro, janeiro e fevereiro cujo rumo é do quadrante oeste (WNW). 
Quadro I - O Potencial de Deriva dos ventos e o seu regime, no posto meteorológico da Praia de Mira. Multimultimodal; bi - bimodal; uni - unimodal.

\begin{tabular}{|c|c|c|c|c|c|}
\hline Mês & Domínio & 2o rumo & Resultante & RDP/DP & Regime \\
\hline Set & N & SW & NNW & 0,19 & multi \\
Out & N & SW & N & 0,52 & bi \\
Nov & SW & N & WNW & 0,34 & multi \\
Dez & N & NW & N & 0,46 & bi \\
Jan & NW & W & WNW & 0,54 & bi \\
Fev & W & NW & WNW & 0,37 & multi \\
Mar & N & NW & NNW & 0,8 & uni \\
Abr & N & NW & NW & 0,54 & bi \\
Mai & N & NW & NNW & 0,7 & uni/bi \\
Jun & N & NW & NNW & 0,48 & bi \\
Jul & N & NW & N & 0,65 & uni/bi \\
Ago & N & NE & N & 0,77 & uni \\
\hline Ano & N & NW & NNW & $\mathbf{0 , 4 9}$ & bi \\
\hline
\end{tabular}

O índice que, porventura, melhor expressa a variabilidade da direção de transporte da areia, ou seja, o seu regime é a relação RDP/DP. Os seus valores mostram que nesta região litoral, o vento é dominantemente bimodal (5 meses), em dois meses varia entre o unimodal e o bimodal, três meses são multimodais e apenas dois são nitidamente unimodais (março e agosto). Quando se faz a média para o ano constatase que o vento domina do quadrante norte, mas o seu regime é bimodal.

\section{Discussão e conclusões}

Um primeiro aspeto, aparentemente estranho, é a variação espacial na atuação do vento eficaz na construção das dunas, em particular as lineares. A distância em causa entre as áreas-amostra das dunas, mesmo entre as extremas com cerca de $40 \mathrm{~km}$, e a planura da topografia envolvente, aponta para a atuação em simultâneo do mesmo tipo de vento. Significa que se terá de recorrer a condições locais particulares para compreender essa diferenciação.

As dunas a sul da Praia de Mira com os abruptos quase todos expostos a norte, logo com uma componente transversa dominante, entende-se pelo efeito barreira desempenhado pela existência do pinhal da Videira Sul, logo a sul da Barrinha de Mira (Fig. 9), sobre os ventos vindos do quadrante norte; atuariam os do quadrante $S$, daí os abruptos com a disposição que têm. Caso semelhante se pode apontar para as dunas transversais dispostas a NE de Quiaios, pelo efeito de barreira aos ventos dos 
quadrantes de S e W efetuado pelo Pinhal do Povo, assinalado desde o séc. XVIII, logo a norte de Quiaios (Almeida, 1997). Apenas os ventos de N e NW atuariam livremente sobre as areias daquelas dunas. Porém, no caso das duas áreas a norte, onde não se conhece a ocorrência de antigas matas que pudessem exercer efeitos de barreira, a situação descrita suscita mais dúvidas do que certezas. Informações orais de idosos locais parecem levantar um pouco do véu: o pinhal das dunas não teria sido semeado todo em simultâneo, mas sim em faixas alternadas; só mais tarde seriam preenchidas as faixas deixadas em vazio. Seria essa a razão para a atuação preferencial dos ventos do norte sobre as dunas logo a norte das faixas plantadas e o mesmo dos ventos sul sobre as dunas logo a sul daquelas faixas? Os anos de intervalo entre as sementeiras seriam suficientes para moldarem as dunas de acordo com o padrão apresentado acima? Falta, para já, confirmar com o plano de sementeira daquelas dunas, caso exista, esta alternância da sua ocupação.

Fig. 9 - Área da amostra da Praia de Mira, em 1914.

(Fonte: Carta da Missão Hidrográfica da Costa de Portugal, no 2, Costa Oeste de Portugal. Entre Espinho e Cabo Mondego, 1914)



O mesmo pinhal que fez de barreira à atuação dos ventos de oeste e sul sobre as dunas a nordeste de Quiaios (Fig. 10) ofereceu resistência à progressão das dunas lineares ocidentais para oriente. Esta afirmação pode ser confirmada pelo desenvolvimento de uma crista de avalanche contínua desde o que se supõe ser o limite norte desse pinhal até junto à povoação de Quiaios, assim como pela subida desmesurada das dunas junto a esse limite, fruto do atraso provocado pelas árvores ao avanço das areias, daí a sua elevação. Significa isto que as dunas se deslocavam para este, ou seja segundo o alinhamento das dunas e não para sul. Além disso, verifica-se 
um maior avanço, sobre o anterior pinhal, na direção da crista da própria duna do que nos seus intervalos, as depressões interdunares, o que corrobora a mesma ideia. No entanto, na direção destas depressões interdunares também se formou crista de avalanche, embora mais pequena, como seria de esperar ${ }^{4}$. Em última instância poderia argumentar-se que dunas transversais em progressão para sul também cresceriam em altura ao contactar com o pinhal, já que o seu limite ocidental tem uma direção NNESSW. Porém se assim fosse, a sua progressão mais lenta sobre os pinheiros criaria um prolongamento atrasado relativamente ao resto da duna, um processo tipo refração, com o desenvolvimento de um gancho para NE, o que não se verifica. Pode concluir-se, então, que se trata de dunas em alongamento e não migradoras (Tsoar, 2001), ou seja, lineares e não transversais.

Fig. 10 - Área de Quiaios com o pinhal imediatamente a norte (Fonte: Carta da Missão Hidrográfica da Costa de Portugal, № 2, Costa Oeste de Portugal. Entre Espinho e Cabo Mondego, 1914)

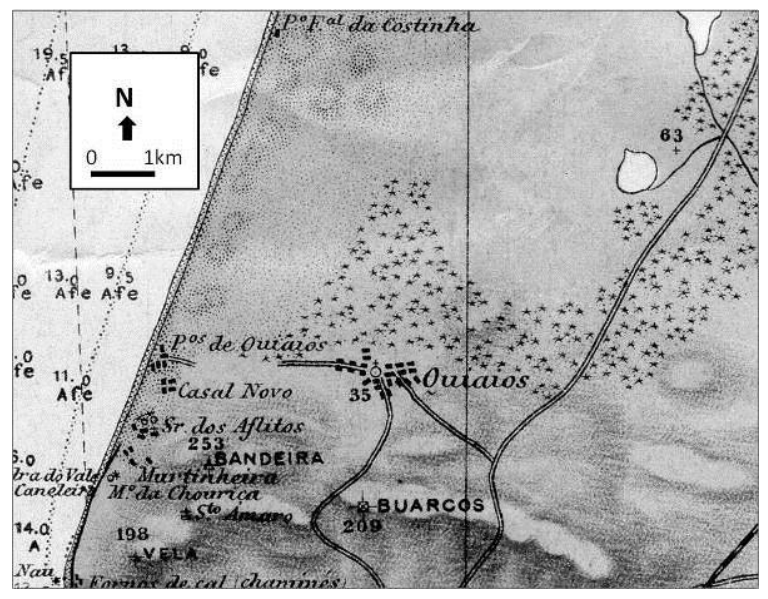

Facto inelutável a retirar destas observações, é que no campo dunar entre Quiaios e Aveiro sempre atuaram ventos de mais do que um quadrante, por vezes quase opostos. Os corpos linguiformes e parabolóides que jazem sobre as cristas de diversas dunas lineares mostram precisamente essa variabilidade de transporte arenoso pelos ventos eficazes.

\footnotetext{
${ }^{4}$ Significa isto que ventos com rumos do quadrante oeste também soprariam e não apenas os do quadrante norte, formadores das ditas dunas transversais. Mas podiam ser de outros rumos desde que oblíquos às cristas, já que, como foi referido acima, quando os ventos são oblíquos à crista da duna sob um ângulo inferior a 40ำ, relativamente a esta, mantêm-se ligados à superfície, defletem e aumentam de velocidade, transportando, portanto, areia para sotavento que, neste caso, será mais ou menos paralelo à duna.
} 
A análise dos ventos de um posto meteorológico na área central deste campo de dunas confirma a variedade de rumos dos ventos eficazes. É um facto que a maioria dos ventos dominantes vêm do quadrante norte, o que pode ajudar a explicar a componente também dominante dos abruptos das vertentes das dunas lineares ser para sul, mas há meses em que o vento dominante ou subdominante é do quadrante oeste, caso de setembro, outubro, novembro, janeiro e fevereiro. Este padrão de ventos dificulta o desenvolvimento de dunas transversais.

Estas conclusões são reforçadas pela análise da deriva potencial associada aos ventos da área, em especial do seu regime, dado pela relação Resultante da Deriva Potencial/Deriva Potencial. A literatura científica diz que as dunas em migração, e.g. transversais e barkanes, formam-se sob ventos unimodais, ou seja com RDP/DP > 0,6; as migrantes, e.g. lineares, sob ventos bimodais, com $0,5<\operatorname{RDP} / D P<0,8$; finalmente as dunas de acumulação, e.g. em estrela, sob ventos multimodais ou bimodais obtusos, com $0<$ RDP/DP < 0,4 (Tsoar, 2001; Fryberger, 1979). Aqui, ventos unimodais apenas dominam em dois meses, os outros meses têm regimes bimodais ou mesmo multimodais (Quadro I).

Como foi mostrado, os aspetos morfológicos das dunas deste campo dunar e as caraterísticas dos ventos que sobre elas sopram e, decerto, sopraram quando da sua formação, não apontam para que haja apenas uma forma de dunas e, mesmo nas lineares, elas não poderão ser exclusivamente, nem sequer dominantemente, transversais. Se o fossem, a sua direção não seria WNW-ESE, mas sim WSW-ENE atendendo às resultantes dos ventos. Também haveria maior regularidade no espaçamento entre as dunas, com valores relacionados com a altura da duna e com o comprimento do vórtice de separação (Hesp \& Thom, 1990).

\section{Referências bibliográficas:}

Almeida, A. Campar (1990). "Os solos na paisagem das dunas de Quiaios". Geografia 9: 151-162.

Almeida, A. Campar (1991). "A morfologia das dunas de Quiaios". Cadernos de Geografia 10: 233-251. 
Almeida, A. Campar (1997). Dunas de Quiaios, Gândara e Serra da Boa Viagem. Uma abordagem ecológica da paisagem. Lisboa, Fundação Calouste Gulbenkian e Junta Nacional Investigação Científica e Tecnológica, Col. Textos Universitários de Ciências Sociais e Humanas, 321 p.

Clarke, M.L., Rendell, H.M. (2006). "Effects of storminess, sand supply and the North Atlantic oscillation on sand invasion and coastal dune accretion in western Portugal." The Holocene 16 (3): 341-355.

Danielsen, Randi; Castilho, A.M.; Dinis, P.A.; Almeida, A.C. \& Callapez, P.M. (2012). "Holocene interplay between a dune field and coastal lakes in the Quiaios-Tocha region, central littoral Portugal." The Holocene 22 (4): 383-395.

Fryberger, Giles (1979). Dune forms and wind regime. A study of global sand seas. E.D. McKee (Ed.). Geological Survey Professional Paper 1052: 137-169.

Hesp \& Thom (1990). Geomorphology and evolution of active transgressive dunefields. Coastal Dunes: Form and Process. K.F. Nordstrom, N.P. Psuty \& R.W.G. Carter (Eds). Chichester, John Wiley \& Sons: 253-288.

Kemp, A.C.; Horton, B.P.; Donnely, J.P.; Mann, M.E.; Vermeer, M. \& Rahmstorf, S. (2011). Climate related sea-level variations over the past two millennia. CNES, Toulouse. In www.pnas.org/content/early/2011/06/13/1015619108.full.pdf Lancaster, N. (1989). "Star dunes." Progress in Physical Geography 13: 67-91. Noivo, Luís M.S. (1996). Morfologia e Dinâmica Sedimentar das Dunas de Quiaios, Portugal. Mestrado, Universidade de Aveiro.

Noivo, L. \& Bernardes, C. (1998). As dunas de Quiaios/Tocha - Sua Morfologia e Evolução. Dunas da Zona Costeira de Portugal. G. Soares de Carvalho, F. Veloso Gomes \& F. Taveira Pinto (Eds.). Leiria, Associação Eurocoast-Portugal: 91-104.

Rei, M. Alberto (1940). Arborização. Alguns artigos de propaganda regionalista. Figueira da Foz.

Tsoar, H. (2001). Types of Aeolian Sand Dunes and Their Formation. Geomorphological Fluid Mechanics. N.I. Balmforth \& A. Provenzale (Eds.). Lecture Notes in Physics, 582: 403-429. 